\title{
Experiência de elaboração de um material técnico gastronômico voltado ao uso sustentável de espécies nativas brasileiras
}

\section{Experience of elaboration of a gastronomic technical material focused on the sustainable use of native Brazilian species}

\author{
Ana Carolina Almada Colucci Paternez ${ }^{1}$ \\ Camila de Meirelles Landi ${ }^{2}$
}

A alimentação adequada é direito fundamental do ser humano e abrange a ampliação das condições de acesso aos alimentos por meio da produção, em especial da agricultura tradicional e familiar, conservação da biodiversidade e utilização sustentável destes recursos. As áreas do conhecimento voltadas para a alimentação, nutrição e gastronomia desempenham papel relevante na valorização e preservação da biodiversidade nativa e na discussão sobre sistemas agroalimentares sustentáveis, com vistas à ampliação do acesso e consumo de alimentos, promoção da economia local e preservação do patrimônio cultural. O presente trabalho apresenta o relato de experiência pedagógica de elaboração de material técnico gastronômico, de natureza interdisciplinar, sobre preservação da biodiversidade brasileira, voltado ao uso sustentável de espécies nativas. A elaboração da pesquisa envolveu docentes e estudantes de graduação dos cursos de Nutrição e Tecnologia em Gastronomia de uma universidade privada de São Paulo. As atividades deste trabalho representam uma ramificação das ações do Projeto Biodiversity for Food and Nutrition, coordenado pelo Bioversity International com as agências implementadoras: Programa das Nações Unidas para o Meio Ambiente e a Organização das Nações Unidas para a Alimentação e a Agricultura. Foram executadas receitas com espécies vegetais nativas da região Sudeste do Brasil, selecionadas no projeto "Plantas para o futuro" do Ministério do Meio Ambiente, com objetivo de compilação e publicação em livro representativo de todas regiões geopolíticas e biomas do Brasil. A etapa de seleção das receitas compreendeu a realização de oficinas de degustação e preparo das receitas propostas para avaliação da viabilidade de execução. Foram realizadas de 3 a 5 preparações para cada espécie, aprovadas na etapa denominada "avaliação sensorial de bancada". As receitas aprovadas foram organizadas em formato de fichas técnicas, com a realização de análise nutricional utilizando os valores apresentados no Banco de dados do Projeto BFN e a Tabela de Composição Química de Alimentos TACO (2004), pelos alunos da Nutrição. Foram realizados os registros fotográficos das espécies in natura e das produções culinárias, com emprego de enxoval gastronômico, equipamentos e técnicas específicas. O trabalho com os estudantes de Nutrição e Gastronomia promoveu a integração dos cursos e aplicação de conhecimentos, como o incentivo ao trabalho de pesquisa e investigação científica. Conclui-se que as instituições de ensino superior (IES), por serem espaços de reflexão, geração de conhecimentos, formação de estudantes para as futuras práticas profissionais e desenvolvimento de pesquisas e tecnologias, são importantes campos reflexivos e propositores de soluções para valorização do patrimônio cultural e promoção da segurança alimentar e nutricional humana. 
Palavras-chave: biodiversidade; educação; espécies nativas; segurança alimentar; nutrição.

Keywords: biodiversity; education; native species; food security; nutrition.

1 Doutora em Saúde Pública pela Universidade de São Paulo, docente da Universidade Presbiteriana Mackenzie.

2 Doutoranda em Educação, Arte e História da Cultura na Universidade Presbiteriana Mackenzie, docente da Universidade Presbiteriana Mackenzie. 